\title{
Burden of Illness Due to Fibromyalgia in a Neurology Clinic
}

\author{
${ }^{1}$ Department of Neurology, Government Medical College Hospital, \\ Kottayam, Kerala, India \\ 2Department of Medical Education, Government Medical College \\ Hospital, Kottayam, Kerala, India \\ ${ }^{3}$ Department of Community Medicine, Government Medical College \\ Hospital, Kottayam, Kerala, India \\ J Neurosci Rural Pract:2020;11:411-415
}

Beena Vasanthy Vijayan ${ }^{1}$ Vijayan Chandrathil Parameswaran Nair ${ }^{2}$ Geethadevi M. ${ }^{3}$

\begin{abstract}
Address for correspondence Beena Vasanthy Vijayan, MD, DM, Department of Neurology, Government Medical College Hospital, Narayaneeyam, Gandhinagar P.O., Kottayam 686008, Kerala, India (e-mail: beenavdr@gmail.com).
\end{abstract}

\begin{abstract}
Keywords

- fibromyalgia

- burden

- clinic

- community
\end{abstract}

Background Fibromyalgia (FM) is a common disorder in general population and it causes an increased patient load in hospitals and specialty clinics. FM attendance will be high in clinics dealing with neuropathic pain and other pain syndromes. Though prevalence of FM has been studied in community and pain clinics in other countries, it has not so far been studied in India. So, a study is relevant and hence it was planned in neurology clinic of a teaching government hospital. At present, they are treated mainly by nonsteroidal anti-inflammatory drugs (NSAIDs) which are public health hazard.

Methods Using 2016 revision of 2010/2011 American College of Rheumatology criteria of FM, patients were screened in neurology OPD. Proportion and clinical profile were noted. Study was continued for 6 months till the sample size was met.

Results A total of 2,300 patients were screened. Two hundred and ninety-eight FM patients were identified among them. Proportion was $12.96 \%$. Delayed diagnosis of more than a year occurred in $55 \%$. Only $29.2 \%$ were treated, but none was offered cognitive behavioral therapy (CBT) before. NSAIDs for pain were given for $51.01 \%$.

Conclusion Proportion of FM detected is considerable. Affection of homemakers and manual laborers, delayed diagnosis, coexisting comorbid illness, and treatment of pain with NSAIDs are causes of concern. Clinicians should be sensitized to clinical profile and criteria of FM. Patients should be diagnosed and treated by CBT at the earliest and NSAIDs should be avoided as far as possible.

\section{Introduction}

Fibromyalgia (FM) is a common disorder, characterized by widespread pain, fatigue, and sleep disturbances. Diagnostic and Statistical Manual of Mental Disorders, Fifth Edition categorized it as a mental disorder, called somatic symptom disorder. ${ }^{1,2} \mathrm{FM}$ is diagnosed by specialists and usually missed by primary care physicians (PCPs). Based on guidelines, FM could be diagnosed with confidence at primary care level and specialty help is needed when mental illness or somatic disease needs exclusion. Criteria put forward from 1990, 2010, and 2016 revision of 2010/2011 are useful to diagnose FM.,34

DOI https://doi.org/

$10.1055 / \mathrm{s}-0040-1712586$

ISSN 0976-3147.
Diagnostic delay of mean period of 2.3 years is common. FM does not have a definite objective evidence and diagnosis is based on clinical criteria. ${ }^{4}$ Hence, classification is feasible by categorizing into a psychiatric disorder. FM is a spectrum of disorders, for diagnostic and research purposes based on clinical criteria. ${ }^{4,5}$ There are 1,990 American College of Rheumatology (ACR) criteria and 2010 criteria, $^{6}$ the ${ }^{7} 2016$ revision of 2010/2011 ACR criteria is more refined for diagnosis by excluding regional pain syndromes.

The knowledge gap is large for FM, compared with other chronic illnesses such as diabetes, asthma, etc. Early diagnosis, cognitive behavioral therapy (CBT), and drug treatment 
with education of both patient and health care provider should be the aim. FM patients should be followed up and all FM features should be addressed simultaneously. Realistic decisions regarding who takes long-term care of FM patients should be made. Thus, FM should be normalized as a chronic illness. ${ }^{8,9}$

Prevalence of FM has been studied in community and in pain clinics in most countries. But in Indian hospital clinics which deal with neuropathic pain and other pain syndromes, prevalence of FM has not so far been studied. The burden of illness due to FM in our society and in our tertiary hospital clinics is not available as there are no published prevalence studies. So, a prevalence study is relevant and hence this study was planned. A qualitative study done in the same clinic earlier found an increased number of FM patients.

\section{Materials and Methods}

FM has significant morbidity with respect to quality of life and the unawareness among PCPs led to consequences such as analgesic nephropathy, gastritis, peptic ulcer diseases, and stroke. Hence, it was planned to study the FM prevalence in neurology outpatient department, which also deals with neuropathic pain syndromes.

With the objective of studying the proportion and clinical profile of FM in neurology clinic, a hospital-based observational study was done in neurology outpatient clinic, Government Medical College Hospital, Kottayam. Adult patients attending neurology clinic who are ambulant, conscious, conversing, and cooperative were included. Patients who had any coexisting neurological or psychiatric illness were excluded. As there are no studies available regarding prevalence of FM in India, a pilot study was done which showed proportion of $6 \%$.

Using this, proportion $(p)$ and formula $N=4 p q / d^{2}$, sample size was calculated as 2,256 . After getting the Institutional Review Board approval, 2,300 patients were screened. Patients were interviewed by the first author using questionnaire 2016 revision to 2010/2011 FM criteria. ${ }^{4}$ Patients who satisfied FM criteria were enrolled. The duration, comorbid illness, consultations made, investigations done, and details of drug treatment were recorded. They underwent physical examination and managed with both CBT and drugs other than nonsteroidal anti-inflammatory drugs (NSAIDs). FM patients were followed up for 3 months and referred back to PCP. Those who did not show response were also referred back with a note for later review.

\section{Results}

Out of 2,300 consecutive patients screened, 298 patients satisfied 2016 revision of 2010/2011 ACR criteria. The proportion was $12.96 \%$. Females formed $93.6 \%$. The majority were between ages 40 and 60 years. Ninety-three per cent had only school education. Homemakers and unskilled laborers formed $86 \%$. Patients with residence in rural area formed 95\%. Comorbid illnesses such as hypertension, diabetes, and hypothyroidism were seen in $41.9 \%$. Diagnostic delay of more than a year occurred in 55\% FM was present in $45 \%$ for less than 1 year, while $25 \%$ suffered more than 5 years (-Tables 1 and $\mathbf{2}$ ).

Seventy per cent patients did not have any treatment, while amitriptyline was prescribed for $16 \%$ and $51.01 \%$ were given NSAIDs. Sixty-six per cent did not have any

Table 1 Baseline data of FM patients

\begin{tabular}{|c|c|c|c|}
\hline & Subdivisions & Number & Percentage \\
\hline \multirow[t]{3}{*}{ Age } & Below 40 & 42 & 14.1 \\
\hline & $40-60$ & 184 & 58.7 \\
\hline & Above 60 & 85 & 28.5 \\
\hline \multirow[t]{2}{*}{ Sex } & Male & 19 & 6.4 \\
\hline & Female & 279 & 93.6 \\
\hline \multirow[t]{5}{*}{ Education } & Illiterate & 4 & 1.3 \\
\hline & Less than 10 th standard & 149 & 50 \\
\hline & 10th-12th standard & 128 & 43 \\
\hline & Degree, PG & 10 & 3.4 \\
\hline & Professional education & 7 & 2.3 \\
\hline \multirow[t]{5}{*}{ Occupation } & Homemakers & 174 & 58.4 \\
\hline & Unskilled work & 82 & 27.5 \\
\hline & Skilled work & 16 & 5.4 \\
\hline & Professional & 24 & 8.1 \\
\hline & Others & 2 & 0.67 \\
\hline \multirow[t]{2}{*}{ Residential status } & Rural & 283 & 95 \\
\hline & Urban & 15 & 5 \\
\hline
\end{tabular}

Abbreviations: FM, fibromyalgia; PG, postgraduation. 
Table 2 Clinical and treatment history of FM patients

\begin{tabular}{|c|c|c|c|}
\hline Major heading & Subdivisions & Number & Percentage \\
\hline \multirow[t]{4}{*}{ Duration of symptoms } & Less than $1 \mathrm{y}$ & 135 & 45.3 \\
\hline & $1-3 y$ & 62 & 20.8 \\
\hline & $3-5 y$ & 27 & 9.1 \\
\hline & More than $5 \mathrm{y}$ & 74 & 24.8 \\
\hline \multirow[t]{3}{*}{ Preconsultations } & Nil & 197 & 66.1 \\
\hline & Once & 63 & 21.1 \\
\hline & More than once & 38 & 12.8 \\
\hline \multirow[t]{4}{*}{ Response to treatment } & Good response & 274 & 91.1 \\
\hline & Moderate & 22 & 7.4 \\
\hline & Mild & 1 & 0.3 \\
\hline & No & 1 & 0.3 \\
\hline \multirow[t]{7}{*}{ Drugs used } & No drugs & 211 & 70.8 \\
\hline & Amitriptyline & 48 & 16.1 \\
\hline & Pregabalin & 3 & 1 \\
\hline & Propranolol & 3 & 1 \\
\hline & Flunarizine & 2 & 0.7 \\
\hline & NSAIDs & 152 & 51.01 \\
\hline & Others and combination & 11 & 3.7 \\
\hline \multirow[t]{7}{*}{ Comorbidities } & Nil & 173 & 58 \\
\hline & Hypothyroidism & 25 & 8.4 \\
\hline & Diabetes mellitus & 24 & 8.1 \\
\hline & Hypertension & 39 & 13.1 \\
\hline & Vascular diseases & 3 & 1 \\
\hline & Connective tissue disorders & 4 & 1.3 \\
\hline & Combinations & 22 & 7.3 \\
\hline
\end{tabular}

Abbreviations: NSAIDs, nonsteroidal anti-inflammatory drugs; FM, fibromyalgia.

prior consultations, while $21 \%$ had single and $13 \%$ had more than one consultations for FM. Patients were kept under follow-up for 3 months and later referred to PCP. Patients were treated with either drug therapy with duloxetine or pregabalin or CBT. Majority showed good response.

\section{Discussion}

The prevalence of FM in the community varies from 1.1 to $6.4 \%{ }^{10}$ In clinics, it is having an increased prevalence, 11 to $13.8 \%$ in various pain clinics of Korea. ${ }^{11}$ In Tel-Aviv Medical Center, it was found that the prevalence is $41.2 \%^{12}$ (another pain clinic). Many studies regarding FM are published, but its prevalence has not been looked into teaching hospital clinic till now. In the present study, it was found to be $12.96 \%$. FM has an increased prevalence in specialty clinic when compared with general population.

FM is found to have an association with small fiber neuropathy. ${ }^{13}$ All subjects under study had various types of pain, some were disabling impairing quality of life. Author was questioned regarding etiology of pain by all patients, revealing knowledge gap. Patients were satisfied when explained regarding small fiber neuropathy and altered pain processing mechanisms, reduced connectivity between pains appreciated areas and other cerebral regions causing increased pain appreciation. ${ }^{14}$ Multifactorial theory of FM with oxidative stress and reactive oxygen species ${ }^{15}$ also came to help.

In addition to pain, patients reported ${ }^{16}$ neurological symptoms such as cognitive abnormalities, headache, vertiginous sensation, subjective unsteadiness, numbness, tingling, sway, giddiness, falls, and fatigue. Cranial nerve symptoms such as photophobia, tinnitus, and dysphagia were also seen. This could be the reason why patients chose to visit neurology clinic even before attending PCP. Dysuria, pelvic pain, and odynophagia were rarely encountered. Gastrointestinal motility disorders were common.

Many neurological patients have $\mathrm{FM}^{17}$ symptoms. FM patients with neurological illness were not included in the present study. It was found that among neurological patients, prevalence of FM is high. Conversely, FM patients had more neurological symptoms such as poor balance, photophobia, sensory and motor symptoms (tingling, numbness, and weakness), dysphagia, etc. than the control group ${ }^{17}$ in published studies. An increased rate of falls were found in FM patients compared with normal controls ${ }^{18}$ but was not addressed in the present study. 
Maximum number of patients were between 40 and 60 years. Patients younger than 40 years were least followed by older than 60 years. Similar finding was reported where younger group (below 29) and older group (above 60) were having reduced prevalence. ${ }^{19}$ Another study did not reveal any findings ${ }^{20}$ in association with age. Community prevalence may be similar and get reflected in clinics.

Females were represented more by 93.6 versus $6.4 \%$ males. This sex ratio is similar to community prevalence, which was reported ${ }^{10}$ where it was 2 versus $0.14 \%$. The striking finding was the absence of alcohol use in majority of male FM patients ${ }^{21}$ which was found here too. Reason could be that alcohol use will alleviate chronic pain (hypothesis only which needs testing).

Fifty per cent of patients did not complete 10 years of formal schooling, while $43 \%$ studied for 12 years. Proportion of illiterate was least, closely followed by professionals. Lower socioeconomic status was associated with increased prevalence and more severe disease. ${ }^{22}$

Occupation-wise homemakers formed majority (58.4\%), followed by unskilled laborers (27.5\%). Professionals represented least, $0.7 \%$. Work demanding increased physical exertion was found to aggravate FM..$^{23}$ This was found before and there should be careful balance of work for FM patients to function without losing workdays.

Ninety-five per cent of FM resided in rural area, while 5\% in urban. This is in contrast to European study where urban FM patients were 0.7 to $11.4 \%$, while rural were 0.1 to $5.2 \%{ }^{24}$ This could be due to increased manual work done in rural India than urban.

Comorbid diseases were absent in 58.1\%. Hypertension was the commonest coexisting disease in $13.1 \%$ followed by hypothyroidism in $8.4 \%$. Diabetes was present in $8.1 \%$ and connective tissue disorders were present in $1.3 \%$. Vascular disease was present in $1 \%$. Though many patients had anxiety and depression and quality of life were impaired, they were not measured. Though there was significant association noticed between connective tissue disorders, only $1.3 \%$ had it while significant proportion had hypothyroidism.

Diagnostic latency was between 6 months and 1 year in $45.3 \%$, while $24.8 \%$ were diagnosed after 5 years. In one study, it was seen that the symptom onset to medical help seeking was 11.1 months and 29\% presented after 6 months of illness. Mean time to receive FM diagnosis was 2.3 years. ${ }^{25}$ Here, diagnosis was early, probably because FM patients presented directly to neurology clinic.

On clinic visit, $70.8 \%$ was not on any specific treatment. NSAIDs were prescribed to $51.01 \%$. In FM, pain is an important symptom and diagnostic delay is common. ${ }^{25}$ NSAIDs associated with renal disease and prothrombotic states. Comorbid diseases such as diabetes, hypertension, and hypothyroidism which are prothrombotic were not uncommon among FM. NSAIDs though not useful is widely prescribed for FM, which are associated with analgesic nephropathy and strokes. Majority of FM patients were on amitriptyline, 16.1\% and other drugs were duloxetine, milnacipran, and pregabalin. ${ }^{26}$
FM patients who consulted one physician were $21.1 \%$ and more than one were $12.8 \%$, before presenting to neurology clinic for treatment. Diagnosis was made for $66.1 \%$ who came to seek medical help for the diseases for the first time in neurology clinic. It could be inferred that neurology clinic is tuned to FM that primary diagnosis were made in $66.1 \%$. Patients were treated with pharmacotherapy and advised for CBT. On follow-up, 91.9\% reported good improvement of their symptoms, while $7.4 \%$ moderate and $0.3 \%$ mild. No improvement was reported by $0.3 \%$. CBT is the mainstay of treatment ${ }^{27}$ and improves by brain connectivity. ${ }^{28}$

\section{Conclusion}

The current one is the first study to report the proportion and clinical profile of FM in a hospital clinic from India is considerable. Increased prevalence was associated with manual labor and had latent period of years before arriving at definite diagnosis. Comorbid disorders such as diabetes, hypertension, and hypothyroidism were not uncommon in FM. Treatment with CBT and recommended drug treatment were not offered prior to presentation. NSAIDs were given to significant proportions which may lead to complications especially in the presence of older age and comorbid diseases.

\section{Conflict of Interest}

None declared.

\section{References}

1 Wolfe F, Walitt BT, Häuser W. Fibromyalgia and the Disease and Statistical Manual Classification as a Somatic Symptom Disorder. Paper presented at the Annual Meeting of American College of Rheumatology. Washington DC. November 9-14, 2012. ABSTRACT NUMBER: 1860

2 Fitzcharles M-A, Shir Y, Ablin JN, et al. Classification and clinical diagnosis of fibromyalgia syndrome: recommendations of recent evidence-based interdisciplinary guidelines. Evid Based Complement Alternat Med 2013;2013:528952

3 Cohen $\mathrm{H}$. Controversies and challenges in fibromyalgia: a review and a proposal. Ther Adv Musculoskelet Dis 2017;9(5):115-127

4 Wolfe F, Clauw DJ, Fitzcharles MA, et al. 2016 revisions to the 2010/2011 fibromyalgia diagnostic criteria. Semin Arthritis Rheum 2016;46(3):319-329

5 Häuser W, Fitzcharles M-A. Facts and myths pertaining to fibromyalgia. Dialogues Clin Neurosci 2018;20(1):53-62

6 Sarzi-Puttini P, Atzeni F, Masala IF, Salaffi F, Chapman J, Choy E. Are the ACR 2010 diagnostic criteria for fibromyalgia better than the 1990 criteria? Autoimmun Rev 2018;17(1):33-35

7 Ablin JN, Wolfe F. A comparative evaluation of the 2011 and 2016 criteria for fibromyalgia. J Rheumatol 2017;44(8):1271-1276

8 Clauw DJ, D’Arcy Y, Gebke K, Semel D, Pauer L, Jones KD. Normalizing fibromyalgia as a chronic illness. Postgrad Med 2018;130(1):9-18

9 Vasanthy B, Parameswaran Nair VC. Fibromyalgia: perspective of patients, medial students and professionals. J Evid Based Med Healthc 2018;5(34):2463-2467

10 Vincent A, Lahr BD, Wolfe F, et al. Prevalence of fibromyalgia: a population-based study in Olmsted County, Minnesota, 
utilizing the Rochester Epidemiology Project. Arthritis Care Res (Hoboken) 2013;65(5):786-792

11 Lee HJ, Choi E, Nahm FS, et al. Prevalence of fibromyalgia in fourteen Korean tertiary care university hospital pain clinics. J Pain Res 2018;11:2417-2423

12 Brill S, Ablin JN, Goor-Aryeh I, Hyat K, Slefer A, Buskila D; Tel Aviv-Sourasky Medical Center. Prevalence of fibromyalgia syndrome in patients referred to a tertiary pain clinic. J Investig Med 2012;60(4):685-688

13 Grayston R, Czanner G, Elhadd K, et al. A systematic review and meta-analysis of the prevalence of small fiber pathology in fibromyalgia: implications for a new paradigm in fibromyalgia etiopathogenesis. Semin Arthritis Rheum 2019;48(5):933-940

14 Flodin P, Martinsen S, Löfgren M, Bileviciute-Ljungar I, Kosek E, Fransson P. Fibromyalgia is associated with decreased connectivity between pain- and sensorimotor brain areas. Brain Connect 2014;4(8):587-594

15 Iqbal R, Mughal MS, Arshad N, Arshad M. Pathophysiology and antioxidant status of patients with fibromyalgia. Rheumatol Int 2011;31(2):149-152

16 Watson NF, Buchwald D, Goldberg J, Noonan C, Ellenbogen RG. Neurologic signs and symptoms in fibromyalgia. Arthritis Rheum 2009;60(9):2839-2844

17 Arias M. [Is fibromyalgia a neurological disease?]. Neurologia 2008;23(9):593-601

18 Meireles SA, Antero DC, Kulczycki MM, Skare TL. Prevalence of falls in fibromyalgia patients. Acta Ortop Bras 2014;22(3):163-166

19 Walitt B, Nahin RL, Katz RS, Bergman MJ, Wolfe F. The prevalence and characteristics of fibromyalgia in the 2012 National Health Interview Survey. PLoS One 2015;10(9):e0138024
20 Cronan TA, Serber ER, Walen HR, Jaffe M. The influence of age on fibromyalgia symptoms. J Aging Health 2002;14(3):370-384

21 Scott JR, Hassett AL, Schrepf AD, et al. Moderate alcohol consumption is associated with reduced pain and fibromyalgia symptoms in chronic pain patients. Pain Med 2018;19(12):2515-2527

22 Fitzcharles MA, Rampakakis E, Ste-Marie PA, Sampalis JS, Shir Y. The association of socioeconomic status and symptom severity in persons with fibromyalgia. J Rheumatol 2014;41(7):1398-1404

23 Palstam A, Mannerkorpi K. Work ability in fibromyalgia: an update in the 21st century. Curr Rheumatol Rev 2017;13(3):180-187

24 Marques AP, Santo ASDE, Berssaneti AA, Matsutani LA, Yuan SLK. Prevalence of fibromyalgia: literature review update. Rev Bras Reumatol Engl Ed 2017;57(4):356-363

25 Choy E, Perrot S, Leon T, et al. A patient survey of the impact of fibromyalgia and the journey to diagnosis. BMC Health Serv Res 2010;10:102

26 Häuser W, Walitt B, Fitzcharles M-A, Sommer C. Review of pharmacological therapies in fibromyalgia syndrome. Arthritis Res Ther 2014;16(1):201

27 Bennett R, Nelson D. Cognitive behavioral therapy for fibromyalgia. Nat Clin Pract Rheumatol 2006;2(8):416-424

28 Lazaridou A, Kim J, Cahalan CM, et al. Effects of cognitive-behavioral therapy (CBT) on brain connectivity supporting catastrophizing in fibromyalgia. Clin J Pain 2017;33(3):215-221 